\title{
26 Research Soure \\ Thixotropy of A Transparent Clay Manufactured by Carbopol Simulate Marine Soil
}

\author{
Zhiwen SUN \\ Hohai University \\ Gangqiang KONG ( $\nabla$ gqkong1@163.com ) \\ Hohai University \\ Yang ZHOU \\ Hohai University \\ Yang SHEN \\ Hohai University \\ Hanyu XIAO \\ Hohai University
}

\section{Research Article}

Keywords: Transparent clay, Carbopol® UltrezTM 10, Transparency, Thixotropy.

Posted Date: January 19th, 2021

DOl: https://doi.org/10.21203/rs.3.rs-147237/v1

License: (c) (1) This work is licensed under a Creative Commons Attribution 4.0 International License. Read Full License 


\section{Abstract}

A transparent clay manufactured by Carbopol $^{\circledR}$ Ultrez $^{\mathrm{TM}} 10$ (simplified as U10) was introduced, and its manufacture processes were briefly described. Both relative transparency (RT) and modulation transfer function (MTF) methods were used to quantify the optical character variation via soil thickness. The transparency of this new transparent clay was comparative analyzed with traditional four previous transparent materials. The results show that this new transparent clay has relative higher optical transparency than majority of previous materials. The thixotropic properties of this synthetic transparent clay were measured in detail through laboratory vane test. Exponential function was used to describe the thixotropy and sensitivity of clay. The good fitting results shown similar development trend of thixotropy for synthetic transparent clay and natural one. Furthermore, sensitivity of transparent clay belongs to low to medium sensitivity, which can simulate marine soil. With the test results, Carbopol ${ }^{\circledR} \mathrm{Ultrez}^{\mathrm{TM}} 10$ shows a great potential as a substitute for natural clay and is expected to be widely used in model tests.

\section{Introduction}

Several innovative transparent materials, which geotechnical properties are similar to natural soils (sand and clay) were used in model tests to study internal displacement, and flow problems (ISKANDER et al. ${ }^{[1]}$; GANIYU et al. ${ }^{[2]}$ ). Transparent sand or clay were manufactured by granular particles and pore fluid with the same refractive index values. Crushed pyrex glass, silica gel, and fused quartz were used to simulate natural sand (ZHAO \& GE ${ }^{[3]}$; GUZMAN et al. ${ }^{[3]}$; KONG et al. ${ }^{[5]}$ ). Amorphous silica (fumed silica aggregate), Aquabeads, Laponite RD and Gelita were used to simulate natural clay (BLACK \& TAKE ${ }^{[6]}$; CHINI et al..$^{[7]}$; DING et al. ${ }^{[8]}$; WALLCE \& RUTHERFORD ${ }^{[9]}$; CAO et al. ${ }^{[10] ;}$ LEl et al. ${ }^{[11]}$ ). These transparent materials were mainly used in model test to study structure penetration, shallow foundation, plant rhizosphere grow, multiphase flow, grout permeation and soil-geosynthetic interaction problems. Transparent soil models can be sliced optically using laser sheets, two-dimensional image of the deformed shape within each slice are obtained by digital image correlation of successive images before and after movement. Multiple slices can be used to construct the complete spatial picture of deformed mass.

Normally, large scaled models using these transparent materials were usually limited by their poor transparency. Hence, select suitable transparent material, which has higher transparency and closer geotechnical properties with natural sand or clay, is still one of the most important work in the near future. The objective of this paper is to develop a new transparent clay manufactured by Carbopol ${ }^{\circledR}$ Ultrez $^{\mathrm{TM}} 10$ (simplified as U10), and comparative analyze on the transparency of this new material with four previous transparent materials (conclude two transparent sand and two transparent clay).

For natural clay, sensitivity is an important property when the strength of clay changes due to external disturbed. The index of sensitivity $\left(S_{t}\right)$ was used to evaluate the structural strength of soft clay.

Thixotropy is one of the important factors that make saturated soft clay sensitive. The thixotropy is the phenomenon that the structure strength of soil decreases sharply when the external force is acted on then 
gradually recover with the increase of time after the cessation. Comparative analyze on thixotropy and sensitivity of the synthetic transparent clay manufactured by U10 with several natural clay was performed in this paper.

\section{Materials And Manufacture Processes 2.1 Materials}

Carbopol ${ }^{\circledR}$ Ultrez ${ }^{\mathrm{TM}} 10$ is a cross-linked polyacrylic acid polymer that provides efficient rheology modification with encased self-wetting for ease of use (FRESNO et al..12]). U10 has many typical features and benefits such as, short floe properties, high viscosity, and high suspending ability. The particle size, specific gravity, and specific surface area of U10 used in this paper are $50 \sim 100 \mathrm{~mm}, 1.4543$, and $0.21 \mathrm{~m}^{2} / \mathrm{g}$, respectively. The photos of U10 powder materials and SEM images of $1 \times 10^{4}, 5 \times 10^{4}$ magnification shown in Figs. 1(a) and 1(b). U10 polymer powders shrinks in contact with water. When the powder disperses in water, the cross-linked acrylic resin chain begins to spread. After neutralizing with an alkaline substance, the polymer becomes expanding structure. From dry polymers to gelled polymers, the volume may increase to 1000 times bigger.

$\mathrm{NaOH}$ powder of fused white particles was chosen as the neutralized material, purity of which is greater than $98 \%$ for analytical reagent (AR). The solution of the $\mathrm{NaOH}$ is strongly alkaline.

The photos of synthetic transparent clay manufactured by U10 are shown in Fig. 1 (c). Speckle field was usually used in transparent soil to investigate the internal deformation problems (KONG et al.. ${ }^{[13]}$ ). Nano materials (carbon nanotubes) are incorporated into the synthetic transparent clay as tracking particles in this paper. The amount of nano materials is about $1 \%$ o by mass, which can be negligible in the mix design. Nanotubes are multi walled (outside diameter and inside diameter are equal to $8 \sim 15$ and $3 \sim$ $5 \mathrm{~mm}$, respectively) materials with appearance of black powder. The specific surface area and density of the material are $233 \mathrm{~m}^{2} / \mathrm{g}$ and $0.15 \mathrm{~g} / \mathrm{cm}^{3}$, respectively. Distinctive speckle pattern under laser sheets can be obtained by camera, shown in Fig. 1(d). This indicates that the new synthetic transparent clay is suitable for the physical model test in deformation investigations.

\subsection{Manufacture processes}

The synthetic transparent clay was manufactured by $\mathrm{U} 10$ powder, $\mathrm{NaOH}$ powder and distilled water. The synthetic transparent clay were prepared at $0.75 \%$ initial mixtures of U10 powder by weight calculated as follows:

Mixture $(\%)=\frac{m_{\mathrm{U} 10}}{m_{\mathrm{IIO} O}+m_{\mathrm{H}_{2} \mathrm{O}}+m_{\mathrm{NaOH}}} \times 100 \%$ 
The manufacture processes of synthetic transparent clay used in this paper contain following steps $(0.75 \%$ mixture was taken as an example):

(1) Safe preparation: Before the manufactured operation, equipment including anti-fog mask, rubber gloves and goggles are prepared in order to prevent the effects of fine particulate materials on human health.

(2) Materials preparation: weighing the amount of U10 powder, $\mathrm{NaOH}$ powder, and distilled water according to the Eq. (1), respectively. For example, $0.15 \mathrm{~kg} \mathrm{U10}$ powder, $0.35 \mathrm{~kg} \mathrm{NaOH}$ powder, and $19 \mathrm{~L}$ distilled water were chosen in this paper.

(3) Mixture of U10 powder: Heating the distilled water to $60 \sim 70{ }^{\circ} \mathrm{C}$ for $3 \sim 4$ hours firstly. Then pouring the U10 powders into the heated water, mixing $30 \sim 40$ minutes by low power agitator, and stand for $3 \sim 4$ hours in airproof condition at room temperature.

(4) Mixture of the $\mathrm{NaOH}$-water solution: dissolving $\mathrm{NaOH}$ powder into $0.5 \mathrm{~L}$ distilled water firstly. Then pouring the $\mathrm{NaOH}$-water solution into the U10-water mixed liquor, and mixing $30 \sim 40$ minutes by high power agitator. Stop mixing when the mixture becomes a smooth paste.

(5) Bubbles clear: If the speckle field is necessary, carbon nanotubes were sprinkled into the transparent clay served as tracer particle. The air bubbles mixed in the sample were removed through vacuuming the sample. The synthetic transparent clay sample was manufactured at last.

\section{Results And Analysis}

\subsection{Transparency analysis}

In order to quantify the optical characteristics of transparent materials, a relative transparency (RT) method was introduced in this paper. Test target with the black background, viewed through transparent materials with different thicknesses ( $24 \mathrm{~mm}$ intervals) were carried out. Test target sign viewed through air and liquid can also be seen in Fig. 2. Camera (Canon 550D) with 18 million effective pixels within $50 \mathrm{~cm}$ distance was used to photo the figures. Photograph the figures through the target layout with different thickness in transparent materials. Pixel intensities ( $/$, grayscale intensity values for black and white equals 0 and 255, respectively) could be obtained for each photo and each window of one photo. Set 0 distance figure as a reference map, the transparency of test target were analyzed, thus reflecting the transparency level of transparent materials. As showed in Fig. 3, the RT values of transparent materials can be calculated as:

$$
\mathrm{RT}=1-\frac{\left(I_{\mathrm{a}}-I_{\mathrm{a}}\right)}{A_{0}}
$$


where RT is the relative transparency, $I_{i}(i \geq 0)$ is the pixel intensity of test target in various depths of transparent materials, $I_{0}$ is the first pixel intensity of the test target placed in air $(0 \mathrm{~mm}$ depth in transparent materials), $A_{0}$ is the pixel intensity of transparent soil.

In order to confirm the superior transparency of this new transparent clay, a comparative test was undergone based on the MTF method (BLACK \& TAKE ${ }^{[6]}$ ). Target are defined by spatial frequency (number of black and white areas) referred to as line pairs per millimeter (lp/mm) (Fig. 3). The MTF defined as follow:

$$
\mathrm{MTF}=\frac{\left(I_{\max (I)}-I_{\min (I)}\right) /\left(I_{\max (I)}-I_{\min (I)}\right)}{\left(I_{\max (0)}-I_{\min (0)}\right) /\left(I_{\max (0)}-I_{\min (0)}\right)}
$$

where $I_{\max ()}$ and $I_{\min (\eta)}$ is the maximum and minimum intensity of an actual object with repeating structure having maximum and minimum intensity $I_{\max (o)}$ and $I_{\min (o)}$, respectively. At low spatial frequencies, the modulation is close to 1 and generally falls as the spatial frequency increases until it reaches zero.

The pixel intensities distribution for test target at $50 \mathrm{~mm}$ depth in difference transparent materials are shown in Fig. 4. It shows that the black test target in this new transparent clay (manufactured by Carbopol ${ }^{\circledR}$ Ultrez $\left.{ }^{\mathrm{TM}} 10\right)$ is more close to test target pixel intensity in air $\left(I_{0}\right)$ than others transparent materials, which indicates better optical transparency properties.

The thickness of transparent soil has a significant effect on the transparency. Therefore, thicknesses of $50,100,150$, and $200 \mathrm{~mm}$ for $0.75 \%$ mixture of U10 powder were used to calibrate the transparency, The RT values of five different transparent materials versus soil thickness are shown in Fig. 5 . The results indicate transparent clay manufactured by $\mathrm{U} 10$ has superior transparency compared with other materials. The comparative MTF values versus soil thickness and spatial frequency for both new transparent clay are shown in Fig. 6 . Targets of $0.02,0.04,0.25$ and $0.50 \mathrm{lp} / \mathrm{mm}$ were used in the transparency calibration, respectively. The results indicate that a linear decrease of transparency with the increasing of the sample thickness. The transparency decreased by $17 \%$ with each increase of $50 \mathrm{~mm}$ measured by MTF method.

\subsection{Thixotropy analysis}

A series of laboratory vane shear tests were performed to investigate the following properties of the transparent clay. The increase in strength with time (thixotropy), the sensitivity, and the measured strength with consolidation after vane insertion were investigated. The laboratory vane shear device used in this paper is a portable type (PS-VST-P). The vane is a four-blade, 50.8 by $101.6 \mathrm{~mm}$ square vane with a rod diameter of $10 \mathrm{~mm}$. The measurement range of the vane shear apparatus is approximately $0 \sim$ $8.125 \mathrm{kPa}$.

Synthetic transparent clay $0.75 \%$ initial U10 mixture was manufactured in the $100 \mathrm{~mm}$ by $100 \mathrm{~mm}$ by $150 \mathrm{~mm}$ cube, and allowed to set or self-weight consolidate for $6 \sim 336$ hours. Laboratory vane tests were 
conducted where the top of the vane was at the depth of $25 \mathrm{~mm}$ below the surface. The on-set of static holding is defined as the moment where the specimen is taken out from the vacuum environment. The sample with $0.75 \%$ initial U10 mixture exhibits an increase in the peak undrained shear strength which is measured by laboratory vane, $S_{u, p e a k}$, with the increasing of time as shown in Fig. 7 . The average peak shear strength of samples undergoing self-weight consolidation for 7 days is $0.28 \mathrm{kPa}$ for $0.75 \%$ mixture. The shear strength of transparent clay is close the one of Harbod mud at liquid consistency (SCHLUE et al. $\left.{ }^{[14]}\right)$. This observation indicates that with self-consolidation alone, the transparent clay remains very soft for an approximate $120 \mathrm{~mm}$ high sample size. The average peak strength of samples undergoing self-weight consolidation for 14 days is $0.3 \mathrm{kPa}$. Therefore, a 7-days setting time was used for testing due to the relatively small increase in undrained shear strength during a second 7-days, similar to transparent clay manufactured by Laponite RD (WALLCE \& RUTHERFORD ${ }^{[9]}$ ).

The thixotropy strength ratio of synthetic clay $\left(0.75 \%\right.$ mixture), $S_{u, p e a k} / S_{u o}$ (original undrained shear strength, $S_{u o}$ ), in comparison with other natural clays is shown in Figs. 8-9. Figure 8 shows the thixotropy ratio change versus logarithmic time. The results indicated similar strength increasing trend between synthetic clay (made by U10) and natural ones. The change trend of thixotropy with time can be described by first order exponential function for clay as shown in Fig. 9, with comparison with several natural clays including Beauharnnois, Detroit, London and Shellhave clay (MORETTO ${ }^{[15]}$ ), Taihu lake and BaiMahu lake dredged slurries (WANG et al. ${ }^{[16]}$ ), Tianjin soft clay (HUO et al. ${ }^{[17]}$ ), other clays (FLAATE ${ }^{[18]}$; TORSTENSSON ${ }^{[19]}$; ROY \& LEBLANE ${ }^{[20]}$ ). The fitting results were shown in Table. 1 , which indicates that transparent clay manufactured by $\mathrm{U} 10$ has similar thixotropic properties.

Table 1. Summury of relationships between thixotropic ratio and time 


\begin{tabular}{|llll|}
\hline Clay & Time $/ \mathbf{h}$ & $\boldsymbol{s}_{u} / \boldsymbol{s}_{u o}=A e^{(-t / t 1)}+\mathbf{B}$ & $\mathbf{R}^{2}$ \\
\hline Beauharnois & $0-10000$ & $=-2.51 e^{(-t / 1547.77)}+3.82$ & 0.981 \\
[15] & & & \\
\hline Detroit [15] & $0-10000$ & $=-0.90 e^{(-t / 2825.81)}+1.90$ & 0.998 \\
\hline London [15] & $0-7200$ & $=-0.81 e^{(-t / 1190.08)}+1.86$ & 0.985 \\
\hline Shellhave [15] & $0-3600$ & $=-0.90 e^{(-t / 90.37)}+1.91$ & 0.964 \\
\hline Taihu Lake[16] & $0-10000$ & $=-0.64 e^{(-t / 450.16)}+1.70$ & 0.962 \\
\hline Baima Lake [16] & $0-10000$ & $=-0.86 e^{(-t / 849.02)}+2.12$ & 0.862 \\
\hline Tianjin coastal clay [17] & $0-48$ & $=-0.26 e^{(-t / 9.30)}+1.20$ & 0.900 \\
\hline Flaate [18] & $0-8$ & $=-0.21 e^{(-t / 0.80)}+1.20$ & 0.998 \\
\hline Bacebol [19] & $0-167$ & $=-0.173 e^{(-t / 2.20)}+1.18$ & 0.957 \\
\hline Askim [19] & $0-167$ & $=-0.165 e^{(-t / 2.20)}+1.17$ & 0.966 \\
\hline St. Alban [20] & $0-167$ & $=-0.156 e^{(-t / 0.45)}+1.16$ & 0.970 \\
\hline St. Louis [20] & $0-26$ & $=-0.200 e^{(-t / 0.17)}+1.20$ & 0.993 \\
\hline Laponite RD [6] & $0-320$ & $=-0.409 e^{(-t / 136.66)}+2.27$ & 0.815 \\
\hline U10 (this paper) & $0-720$ & $=-2.080 e^{(-t / 119.78)}+2.93$ & 0.920 \\
\hline
\end{tabular}

The sensitivity of soil is an indication of the reduction in shear strength of soil when disturbed, e.g. when it is remoulded or when it is subjected to monotonic or cyclic loading. The soil sensitivity is defined as the ratio of the undrained shear strength of undisturbed soil to the undrained shear strength of the remoulded soil at the same water content, e.g. $\mathrm{S}_{\mathrm{t}}=\mathrm{S}_{\mathrm{u}} / \mathrm{S}_{\mathrm{ur}}$ (where $\mathrm{S}_{\mathrm{u}}$ and $\mathrm{S}_{\mathrm{ur}}$ is the undisturbed undrained shear strength, and remoulded undrained shear strength, respectively). The ratio of the peak undisturbed strength to the remoulded strength, as determined by the unconfined compression test, was used initially by Terzaghi as a quantitative assessment of sensitivity. However, the strength of some clays is so low that unconfined compression test specimens cannot be used. Therefore, the laboratory vane shear test was used in this paper. The remolded shear strength was measured by manually rotating after obtaining the peak shear strength and performing an additional laboratory test. Figure 10 shows that the peak strength and residual strength change versus time, while the corresponding change of sensitivity with time developing is shown below. The sensitivity versus time of transparent clay also can be fitted by exponential function, similar to natural one (e.g. layer No. 4 soft clay in Shanghai). The sensitivity of synthetic clay ranges from low to medium sensitivity. Nevertheless, the synthetic clay belongs to low sensitive clay for other classification standards (ABUHAJAR et al. ${ }^{[21]}$ ), as shown in Fig. 11. 


\section{Conclusions}

One new transparent clay manufactured by Carbopo|® Ultrez ${ }^{\mathrm{TM}} 10$ (referred to as U10) and its manufacture processes are introduced. The main conclusions drawn from this paper are as follow:

(1) The transparency of new transparent clay manufactured by U10 was quantified by RT and MTF methods. The transparency of this new transparent clay was measured and comparative analyzed with four previous transparent materials (fumed silica aggregate, aquabeads, fused quartz, and crushed pyrex glass). The transparent clay introduced in this paper is obviously better than majority of previous materials through RT analysis. Furthermore, the transparency decreased by $17 \%$ with each increase of $50 \mathrm{~mm}$ measured by MTF method.

(2) The peak strength of synthetic transparent clay $(0.75 \%$ U10 mixture) by laboratory vane shear test during 7 days measures from 0.26 to $0.30 \mathrm{kPa}$, which is within the range of those of Harbor mud at liquid consistency $\left(0.25 \sim 0.43 \mathrm{kPa}\right.$, after SCHLUE et al. $\left.{ }^{[16]}\right)$.

(3) The obvious thixotropy occurrence is quite consistent with natural clay. Exponential function is used to describe the change trend of thixotropy with time for transparent clay and other natural clays. Results indicate similar development trend versus between synthetic clay and natural one. What is more, the synthetic transparent clay should be divided into low to middle sensitive clay for the sensitivity of 2.8 3.4. The results indicate good perspective for future development for transparent clay.

\section{References}

1. ISKANDER, M. BATHURST, R. J., OMIDVAR, M. Past, present, and future of transparent soils [J]. Geotech. Test. J. 38, 557-573 (2015).

2. GANIYU, A. A., RASHID, A. S. A. \& OSMAN, M. H. Utilisation of transparent synthetic soil surrogates in geotechnical physical models: A review [J]. Journal of Rock Mechanics and Geotechnical Engineering. 8 (4), 568-576 (2016).

3. ZHAO, H. GE, L. Investigation on the shear moduli and damping ratios of silica gel [J]. Granular Matter. 16, 449-456 (2014).

4. GUZMAN, I. L. \& SUESCUN-FLOREZ, I. S. K. A. N. D. E. R. M. E., OMIDVAR, M. A. Transparent aqueoussaturated sand surrogate for use in physical modeling [J]. Acta Geotech. 9, 187-206 (2014).

5. KONG, G. Q., WANG, Z. H. O. U. L. D., YANG, Z. T. \& LI, G. H. Shear modulus and damping ratios of transparent soil manufactured by fused quartz [J]. Materials Letter. 182, 257-259 (2016).

6. BLACK, J. A. TAKE, W. A. Quantification of optical clarity of transparent soil using the modulation transfer function [J]. Geotech. Test. J. 38, 588-602 (2015).

7. CHINI, C. M. \& RUTHERFORD, W. A. L. L. A. C. E. J. F. C. J., PESCHEL, J. M. Shearing failure visualization via particle tracking in soft clay using a transparent soil [J]. Geotech. Test. J. 38, 708724 (2015). 
8. DING, X. H., LU, Z. H. O. U. W. \& GAO, X. Y. Physical simulation test of soil-rock mixture from synthetic transparent soil [J]. Journal of Central South University. 25, 3085-3097 (2018).

9. WALLCE, J. F. RUTHERFORD, C. J. Geotechnical properties of Laponite RD [J]. Geotech. Test. J. 38, 574-587 (2015).

10. CAO, Z. H., LIU, H. L., KONG, G. Q. \& ZHOU, H. Physical modeling of pipe piles under oblique pullout loads using transparent soil and particle image velocimetry [J]. Journal of Central South University. 22, 4329-4336 (2015).

11. LEI, H. Y. \& LIU, Y. N. ZHAI, S. B., TU, C. K., LIU, M. Visibility and mechanical properties of transparent clay [j]. Chinese Journal of Geotechnical Engineering. 41 (S2), 53-56 (in Chinese) (2019).

12. FRESNO, M. J. C., RAMIREZ, A. D. \& JIMENEZ, M. M. Systematic study of the flow behaviour and mechanical properties of Carbopol ${ }^{\circledR}$ Ultrez $^{\text {TM }} 10$ hydroalcoholic gels [J]. European Journal of Pharmaceutics and Biopharmaceutics. 54 (3), 329-335 (2002).

13. KONG, G. Q. \& CAO, Z. H. ZHOU, H., SUN, X. J. Analysis of piles under oblique pullout load using transparent soil models [J]. Geotech. Test. J. 38 (5), 725-738 (2015).

14. SCHLUE, B. F., MOERZ, T. \& KREITER, S. Influence of shear rate on undrained vane shear strength of organic harbor mud [J]. Journal of Geotechnical and Geoenvironmental Engineering. 136 (10), 14371447 (2010).

15. MORETTO, O. Effect of natural hardening on the unconfined compression strength of remoulded clays//Proceedings of the 2nd International Conference on Soil Mechanics and Foundation Engineering, Rotterdam, the Netherlands. 1948, 1: pp. 137-144.

16. WANG, L. \& CAO, L. L. LI, I. Vane shear tests on thixotropy of Taihu lake and BaiMahu lake dredged slurries [J]. Journal of Engineering Geology. 23 (3), 548-553 (in Chinese) (2015).

17. HUO, H. F. \& QI, L. LEI, H. Y., YU, G. Analysis and experimental study on thixotropy of Tianjin soft clay [J]. Chinese Journal of Rock Mechanics and Engineering. 35 (3), 631-637 (2016).

18. FLAATE, K. Factors influencing the results of vane tests [J]. Can. Geotech. J. 3 (1), 18-31 (1966).

19. TORSTENSSON, B. A. Time-dependent effects in the field vane test[A]. //Proc., Int. Symp. on Soft Clay. Bangkok: Asian Institute of Technology [C] 1977: pp. 387-397.

20. ROY, M. LEBLANC, A. Factors affecting the measurements and interpretation of the vane strength in soft sensitive clays//Vane Shear Strength Testing in Soils: Field and Laboratory Studies. ASTM International 1988.

21. ABUHAJAR, O., EL-NAGGAR, M. H. \& NEWSON, T. Review of available methods for evaluation of soil sensitivity for seismic design [C]. Fifth International Conference on Recent Advances in Geotechnical Earthquake Engineering and Soil Dynamics [C]. San Diego, California, USA 2010.

\section{Figures}



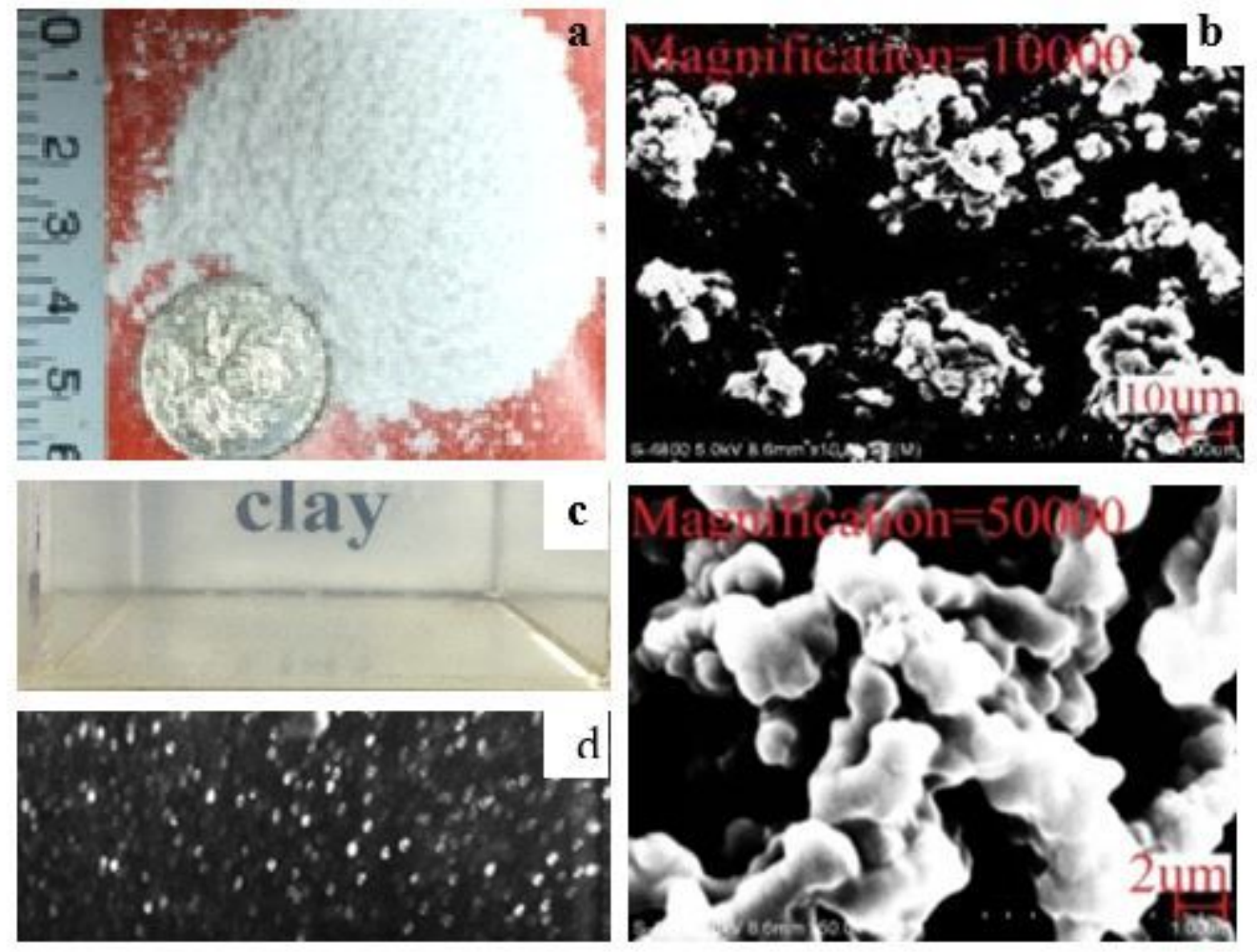

Figure 1

Photos of Carbopol ${ }^{\circledR}$ Ultrez 10 polymer material: a- powder; b- SEM images; c- $17 \mathrm{~cm}$ thickness transparent clay; d-speckle pattern.

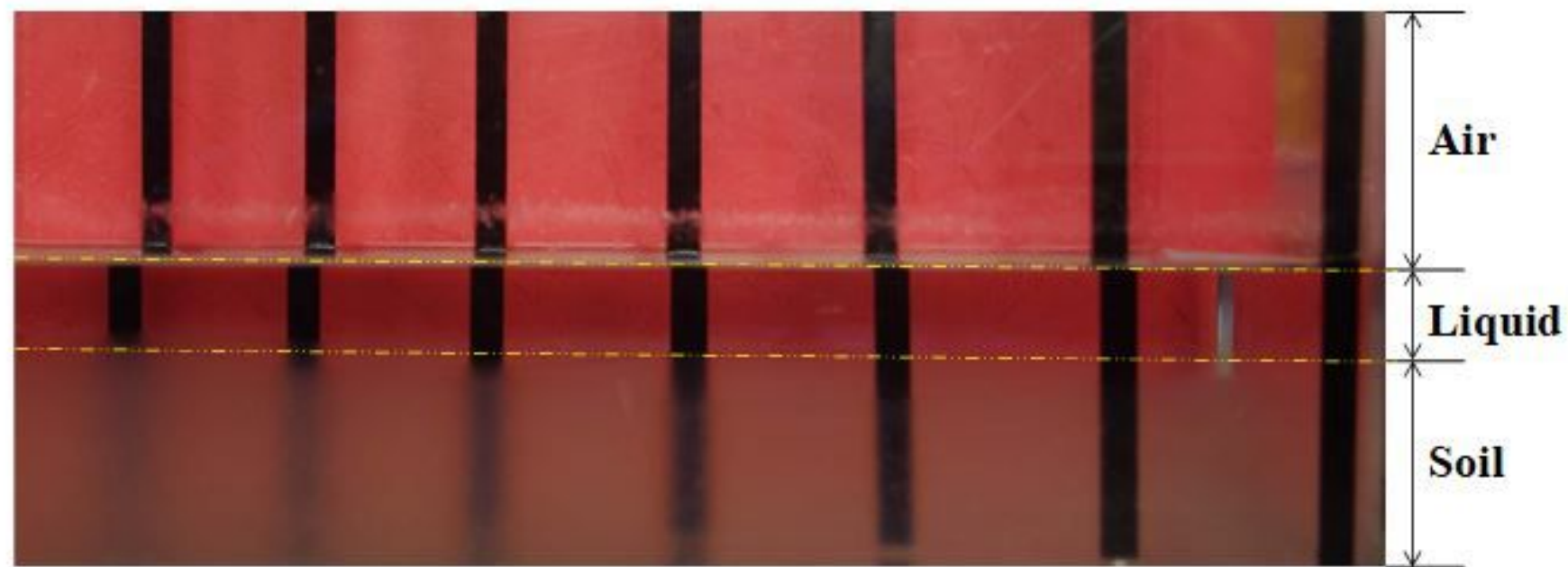

Distance (mm)

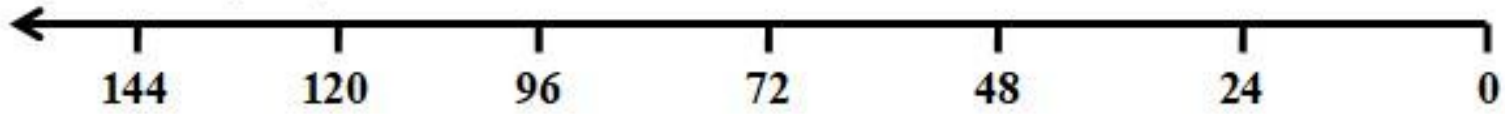


Figure 2

Sign viewed through different thickness of transparent material (e.g. fused quartz).

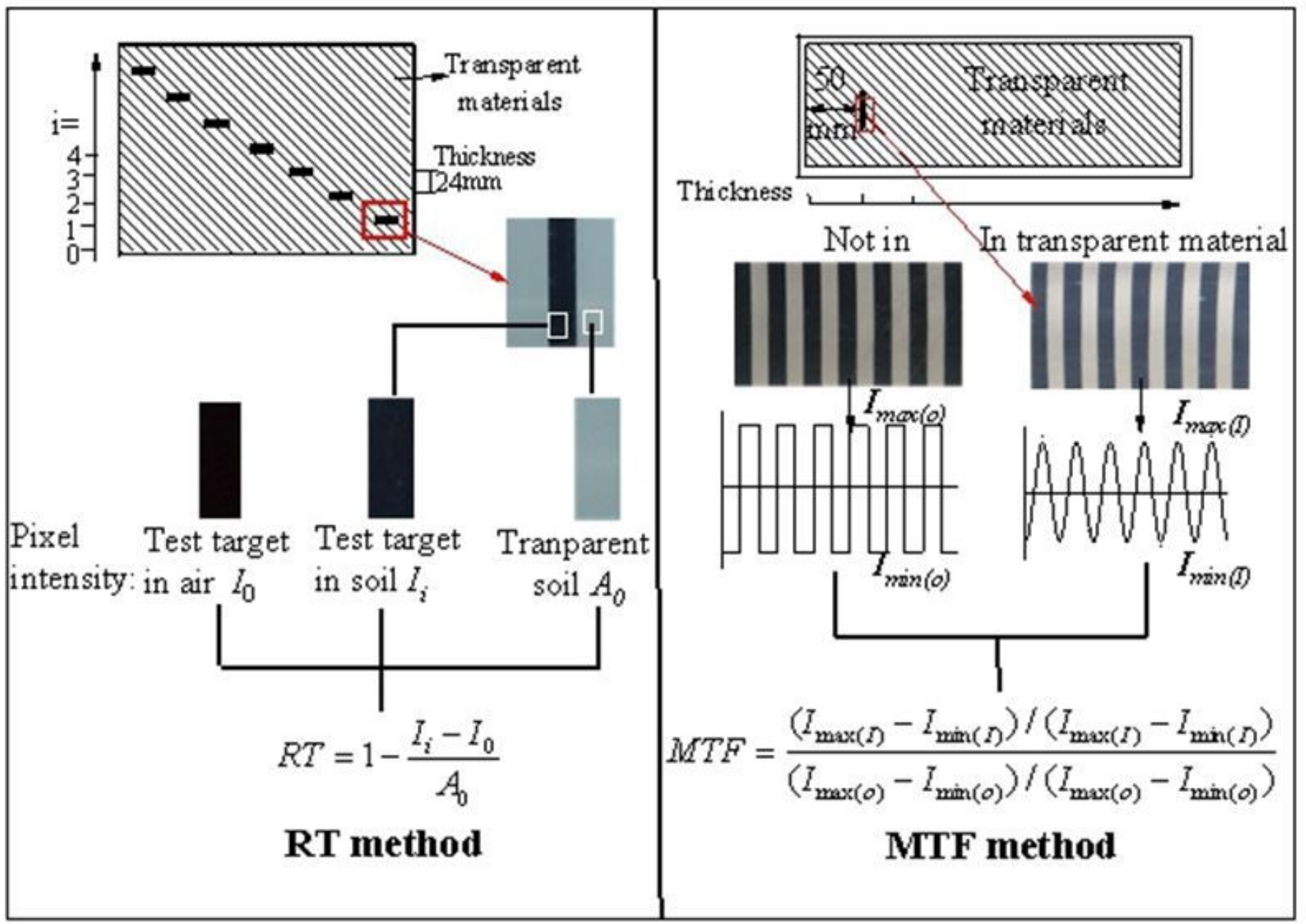

Figure 3

Calculation diagram: a- RT and MTF methods. 


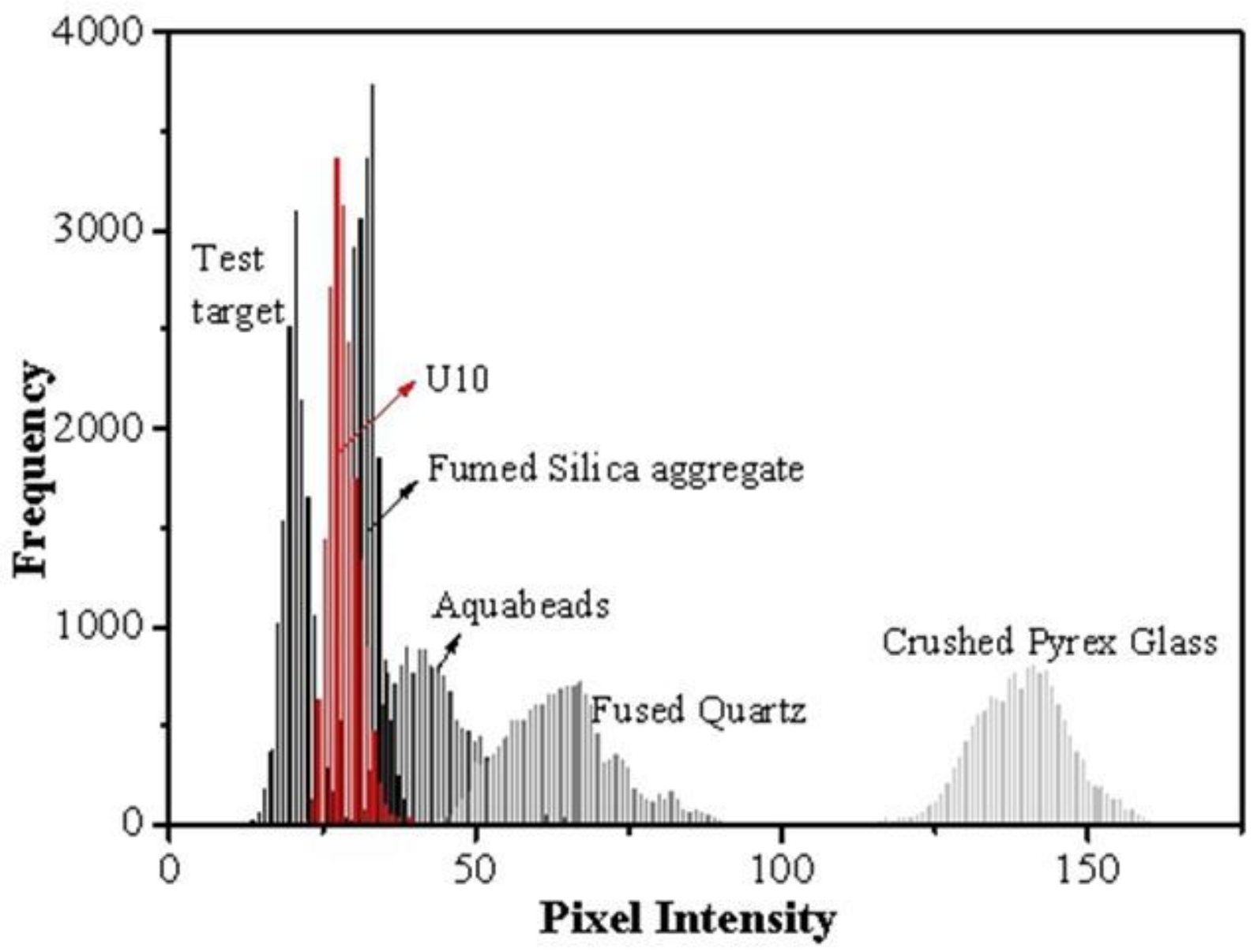

Figure 4

Pixel intensity frequency of test target in transparent medium of $50 \mathrm{~mm}$ thickness. 


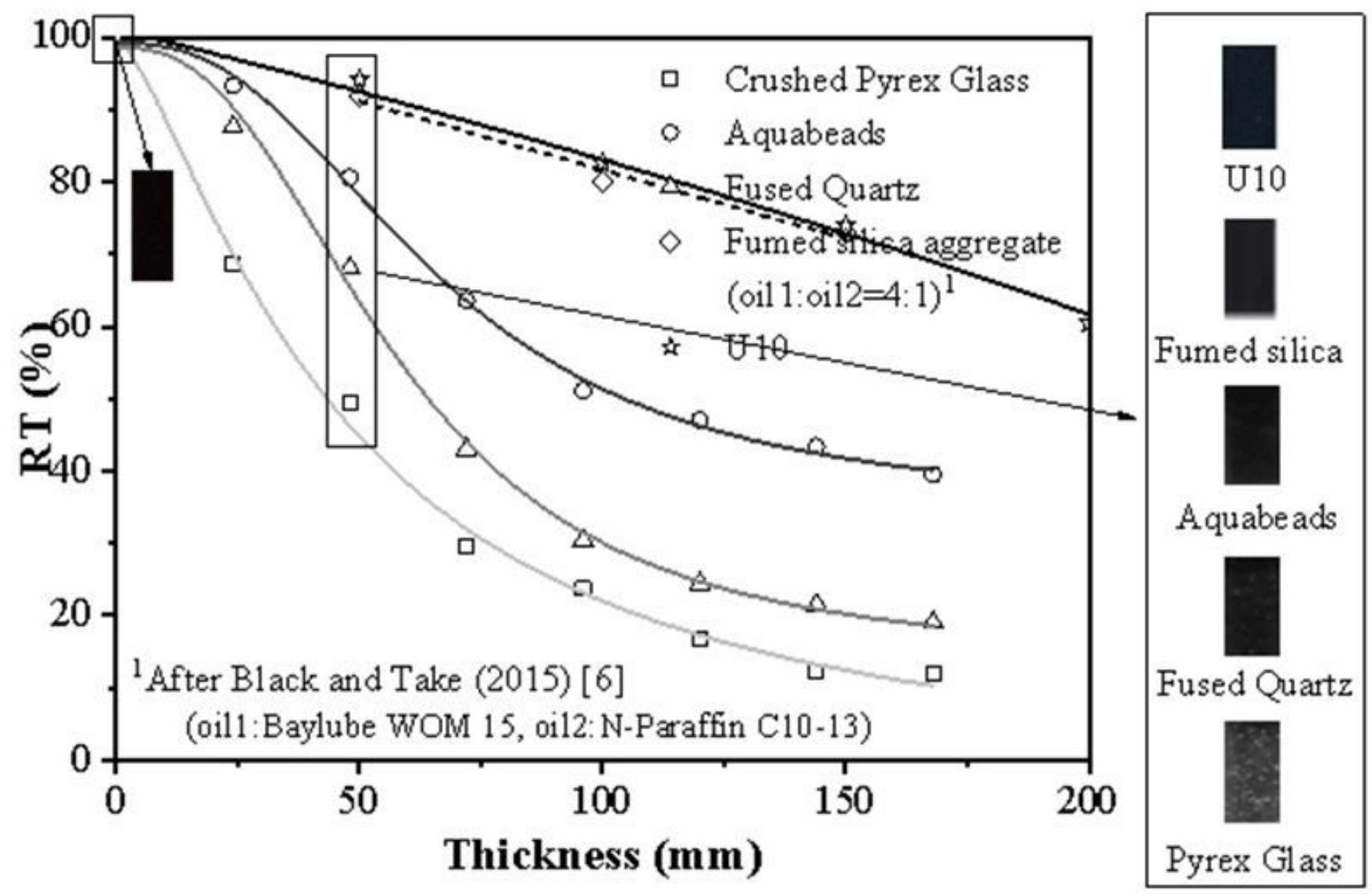

Figure 5

Transparency of materials versus soil thickness from RT method. 
Spatial frequency-

line p airs per $\mathrm{mm}(\mathrm{p} / \mathrm{mm})$

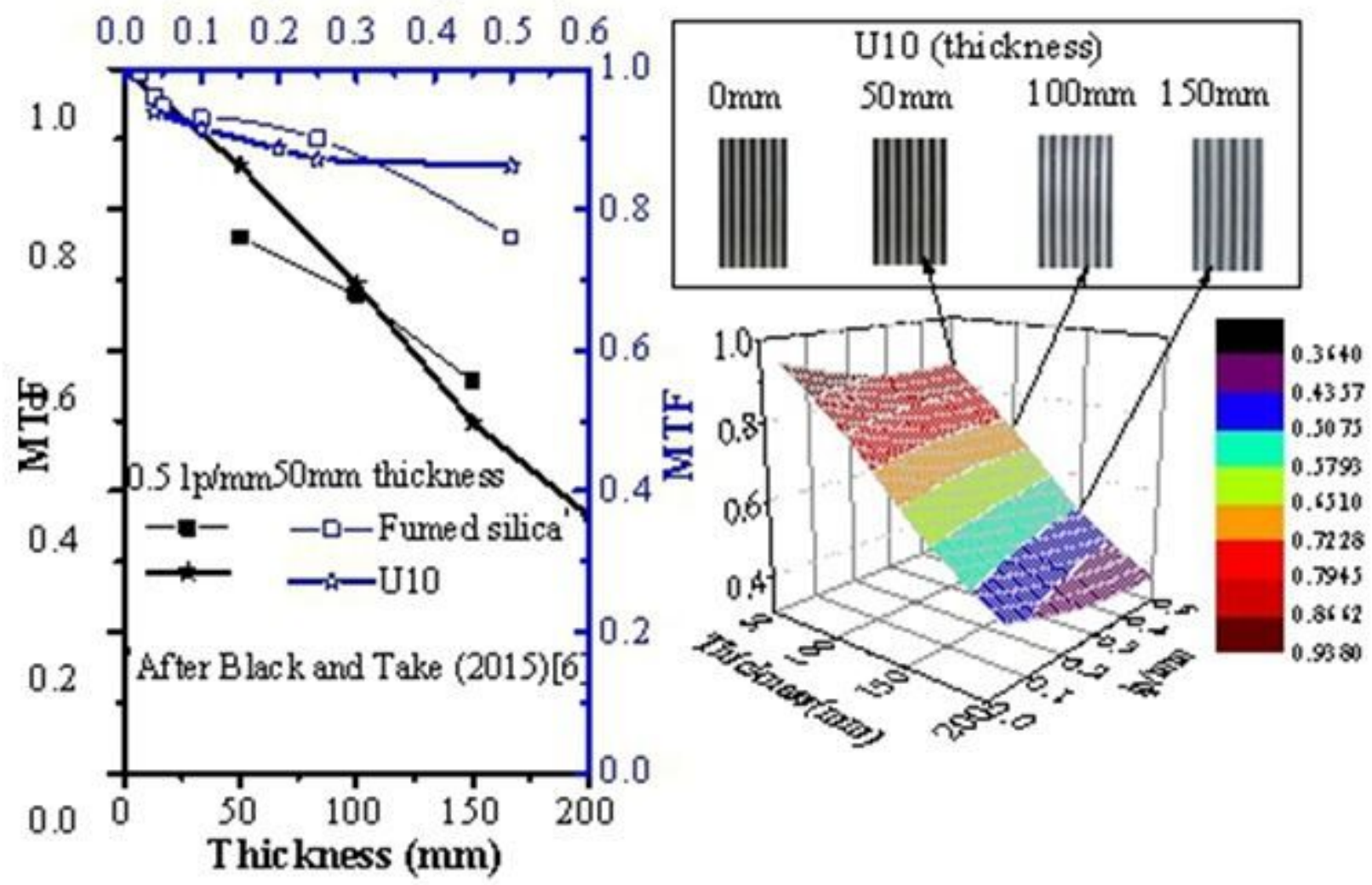

Figure 6

Transparency of materials versus soil thickness and spatial frequency from MTF method. 


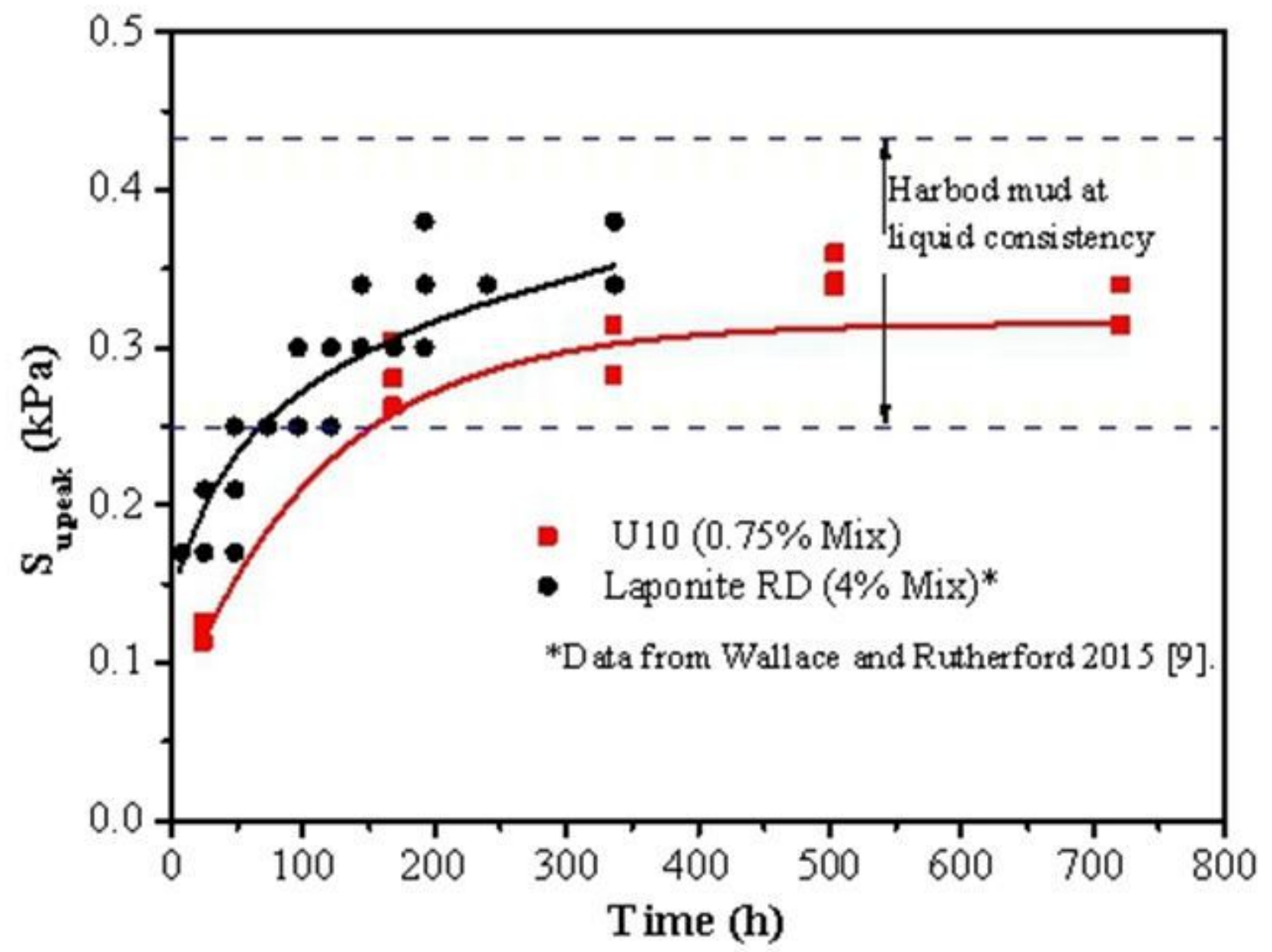

Figure 7

Peak undrained shear strength measured by laboratory vane shear test for $0.75 \%$ initial mixture. 


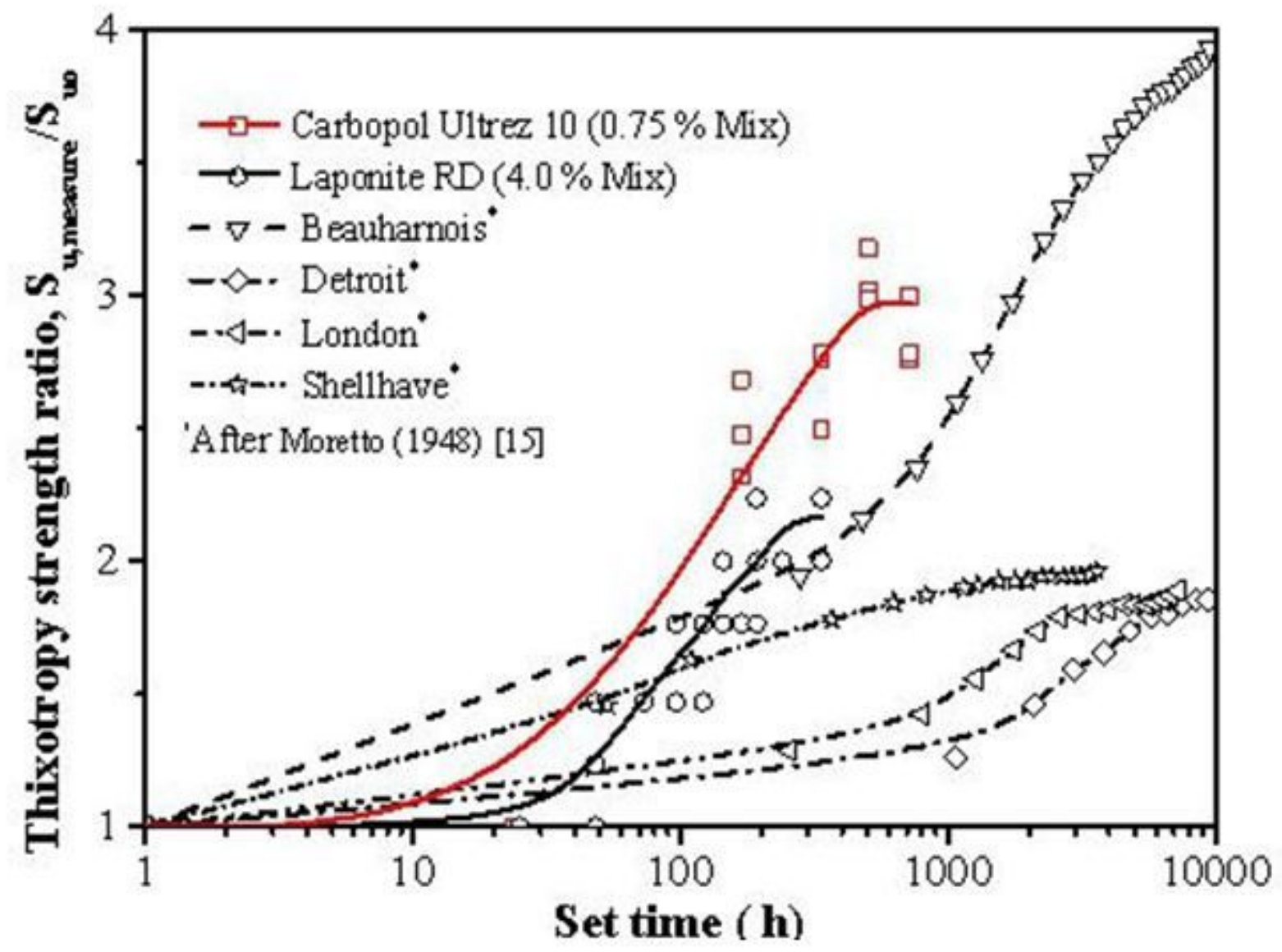

Figure 8

Thixotropy strength ratio for transparent clay of $0.75 \%$ initial mixture. 

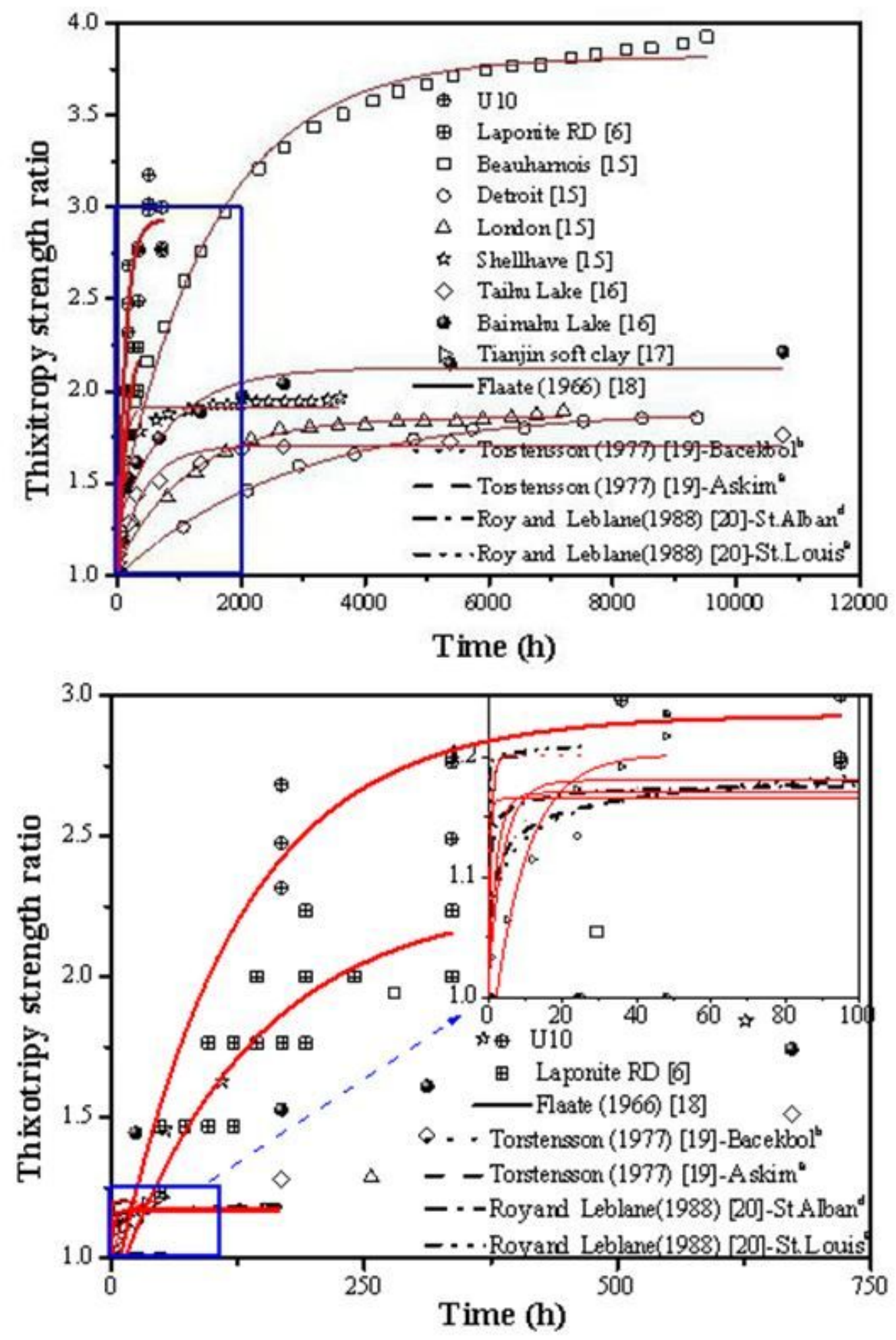

Figure 9

Thixotropy strength ratio for transparent clay compared with natural clay. 


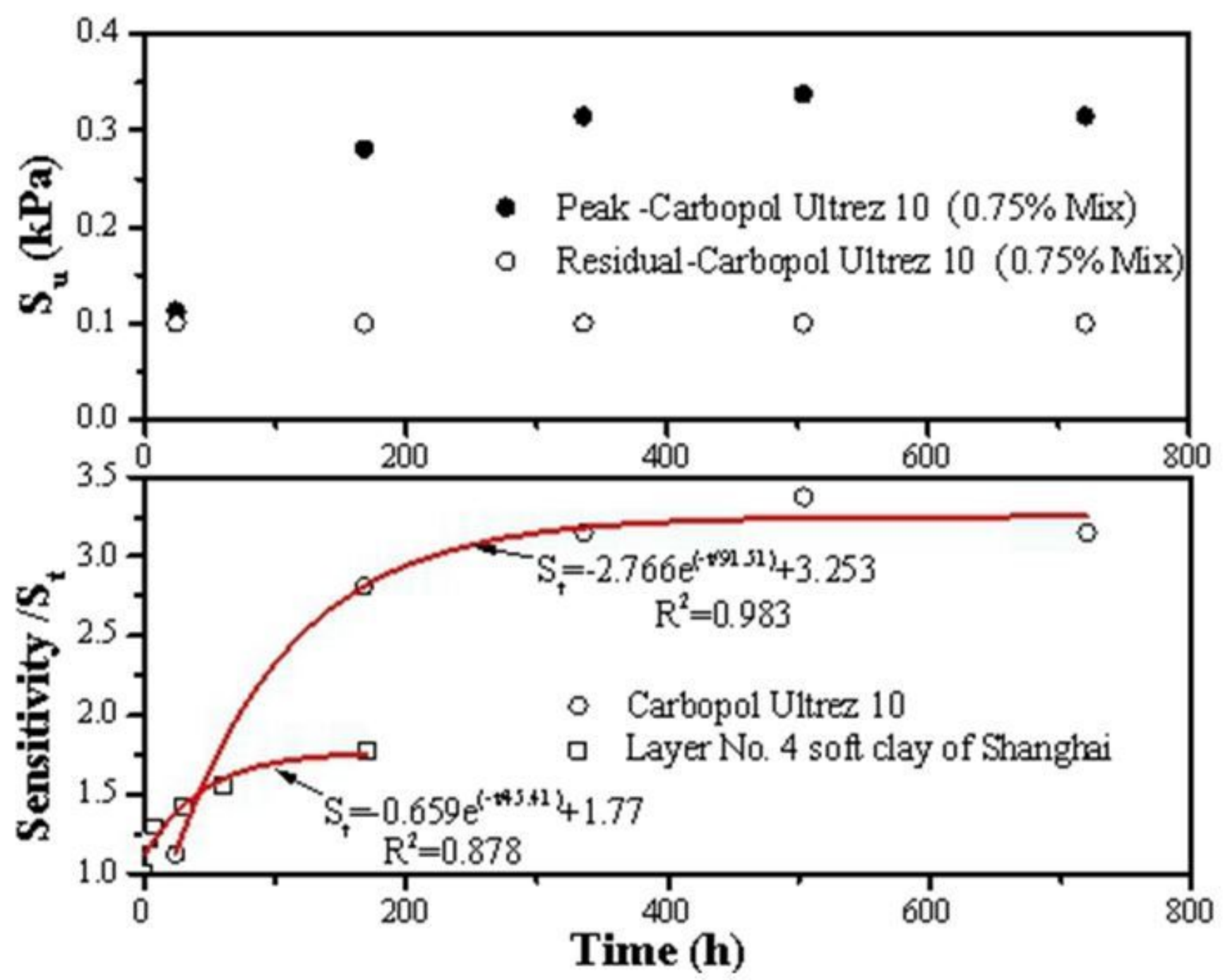

Figure 10

Sensitivity measured by laboratory vane shear test: Peak and residual strength, and sensitivity versus time. 


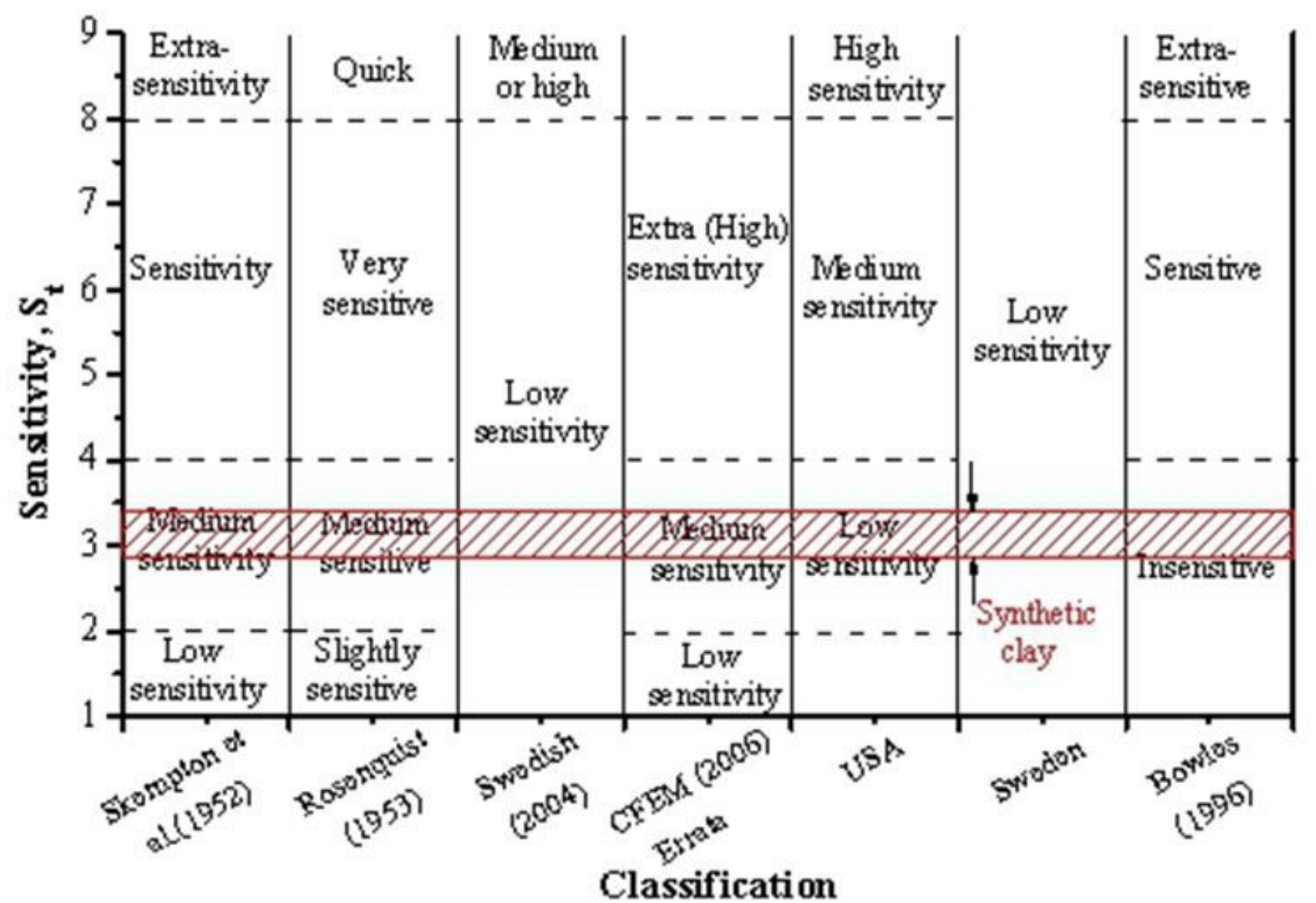

Figure 11

The classification of sensitivity. 